\title{
The Effect of Body Shape Type on Differentiability of Traditional and Geometric Morphometric Methods: A Case Study of Channa gachua (Hamilton, 1822)
}

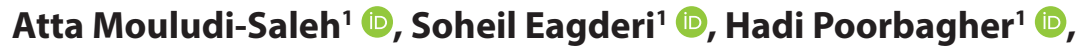 \\ Shirin Kazemzadeh' ${ }^{1}$ \\ 'University of Tehran, Faculty of Natural Resources, Department of Fisheries, Karaj, Iran
}

ORCID IDs of the authors: A.M.S. 0000-0002-0939-0901; S.E. 0000-0001-8649-9452; H.P. 0000-0003-0546-8713; S.K. 0000-0003-0253-4148

Please cite this article as: Mouludi Saleh A, Eagderi S, Poorbagher H, Kazemzadeh S. The Effect of Body Shape Type on Differentiability of Traditional and Geometric Morphometric Methods: A Case Study of Channa gachua (Hamilton, 1822). Eur J Biol 2019; 78(2): 165-168. DOI: 10.26650/EurJBiol.2019.0011

\begin{abstract}
Objective: The morphological differences of two populations of the Dwarf snakehead, Channa gachua (Hamilton, 1822) from Sarbaz (Makran basin) and Halil (Hamun-e Jaz Murian basin) rivers were studied using geometric and traditional morphometrics (GM and TM) methods to test the hypothesis that the type of body shape can produce different results.

Materials and Methods: A total of 16 landmark-points and 12 distance measurements were defined to analyse the body shape differences and the extracted data were analyzed using GM and TM methods.

Results: Our findings reject the hypothesis, and the results revealed that GM is more effective in detecting meticulous morphological differences.

Conclusion: In addition, the results suggest selecting a proper method i.e. GM or TM, based on the degree of accuracy needed i.e. if we need to find small shape differences within its signification, GM is a superior technique, or to show the type of differences, then we can use TM.
\end{abstract}

Keywords: Freshwater Fish, Morphology, Phenotypic Plasticity, Generalized Procrustes Analysis

\section{INTRODUCTION}

Comparative studies on the body shape in fishes are commonly used to understand many aspects such as resource management, evolution, behaviour, ecology and phenotype plasticity (1-6). In many works, which have investigated the morphological variation of the biological structures using traditional (TM) (7-9) and geometric morphometric (GM) (10-17) techniques, it has been suggested that $\mathrm{GM}$ is more effective to detect morphological disparities $(4,8)$. Additionally, it have been shown that both methods can lead to similar (12) or different results (9).
It bring to us this hypothesis that such differences may be related to the body shape type of the studied organisms. For instance, if a fish's body shape is simple, then we can expect similar results of both TM and GM methods; and if the body shape is complex, then we can expect a different result. Therefore, this study was conducted to compare the body shape of the dwarf snakehead, Channa gachua, using TM and GM methods.

Channa gachua is a species with large head scales and elongate dorsal and anal fins, and with the ability to breathe from air inhabiting tropical and sub-tropical water bodies (18). It is a fish species with a bottom rover 


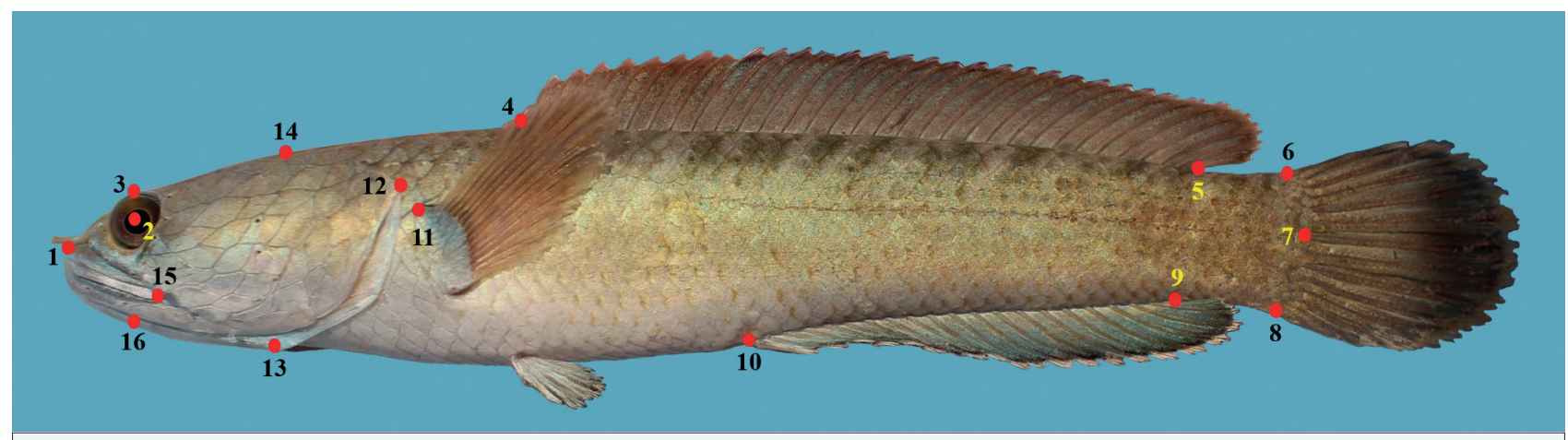

Figure 1. Defined landmark-points to extract the body shape data of Channa gachua. (1) anterior-most point of the snout tip on the upper jaw, (2) center of the eye, (3) dorsal edge of the head perpendicular to the center of eye, (4) origin and (5) insertion point of the dorsal-fin base, (6) postero-dorsal end of the caudal peduncle at its connection to the caudal fin, (7) posterior end of the medial region of the caudal peduncle, (8) postero-ventral end of the caudal peduncle at its connection to the caudal fin, (9) insertion and (10) origin point of the anal-fin base, (11) most anterior point of the pectoral fin, (12) posterior edge of the opercle, (13) ventral end of the gill slit, (14) the line extends perpendicularly to the most basic part of the gill slit above the head, (15) The terminus of the oral clefts in the upper jaw and (16) ventral edge of the head perpendicular to the center of eye.

body shape pattern i.e. a simple body shape that expects the same results of both TM and GM methods. The biggest population of this species in the western Asia, is found in the Makran, Mashkid and Hamun-e Jaz Murian basins of Iran (18).

\section{MATERIALS AND METHODS}

In total, 40 specimens of $C$. gachua representing two different populations were collected from the Halil ( $n=17,28^{\circ} 40^{\prime} 29.43^{\prime \prime} \mathrm{N}$, $57^{\circ} 42^{\prime 22.96 " E, ~ H a m u n-e ~ J a z ~ M u r i a n ~ b a s i n) ~ a n d ~ S a r b a z ~(~} \mathrm{n}=$ 23, 26 $37^{\prime} 47^{\prime \prime} \mathrm{N}, 61^{\circ} 15^{\prime} 31^{\prime \prime} \mathrm{E}$, Makran basin) rivers using an electrofishing device (Samus MP750). After anesthesia, the left sides of the fresh collected specimens were photographed using a copy-stand equipped with a digital camera (Kodak EasyShare Z650 with a 6 MP resolution) with fins erected by insect pins. Then, the sampled specimens were fixed in the buffered formalin and transferred to a laboratory.

For the GM method, a total of 16 homologous landmark-points were digitized using tpsDig2 software (version 2.16) (Figure 1) on 2D pictures. A Generalized Procrustes analysis (GPA) was used to remove non-shape data, including size, position and direction. The resulting data were analyzed using discriminant function analysis (DFA) and Hotelling's T-test to investigate the morphological distinction between the populations. Morphological disparities between the populations were visualized using deformation grids in MorphoJ software.

For the TM method, 12 distance measurements, including SL (standard length), SnL (snout length), ED (eye horizontal diameter), HL (head length), HW (maximum head width), HDO (head depth at posterior edge of the opercle), HDE (head depth at middle of the eye), BD (body depth at dorsal-fin origin), DFL (dorsal-fin length), AFL (anal-fin length) and CPL (caudal peduncle length) were taken using dial calipers to the nearest $0.1 \mathrm{~mm}$. To remove the size from data, they were standardized using the Beacham formula as following (19):

$$
M_{(t)}=M_{(0)}\left(\frac{L}{L_{(0)}}\right)^{b}
$$

Where $M_{(t)}$ is standardized values of characters, $M_{(0)}=$ characters of the observed length $L=$ standard length mean of all samples, $L(0)=$ a standard length of each sample and $b=$ regression coefficient between $\log L_{(0)}$ and $\log M_{(0) \text {. }}$.

Analyses for GM method were performed using PAST and MorphoJ (version 1.01) softwares. Levin's test and DFA/ Hotelling's T-test in TM method were performed in SPSS V.19 and PAST software, respectively.

\section{RESULTS AND DISCUSSION}

\section{Geometric Method}

DFA and Hotelling's T-test showed that the two populations can be significantly differentiated in terms of the body shape $(P>0.0001)$ (Figure 2). The wireframe of the body shape showed differences in position of the snout and caudal peduncle length. In the Halil River population, the body was deeper and the eyes

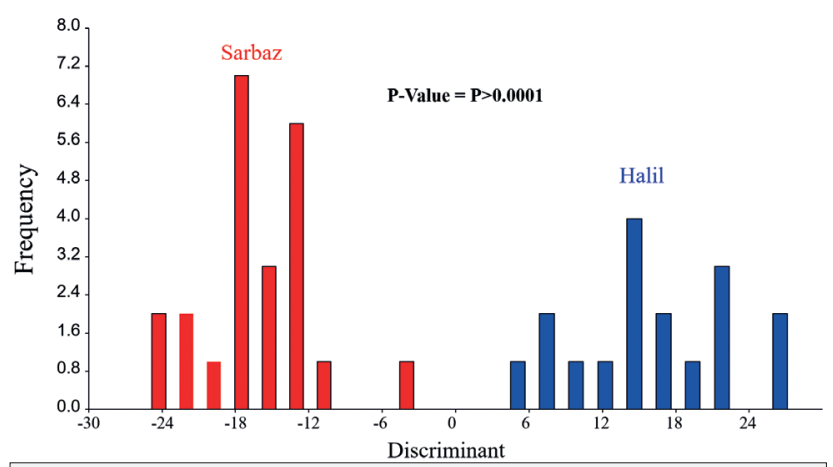

Figure 2. Discriminant function analysis of Channa gachua populations from the Halil and Sarbaz rivers in GM method. 
Table 1. Levin's test and mean ( \pm standard deviation) of each morphological character measured in Channa gachua from Sarbaz and Halil rivers populations (All measurements are shown in $\mathrm{mm}$. Variables for which significant differences were obtained are highlighted in bold).

\begin{tabular}{|c|c|c|c|c|}
\hline Characters & Sarbaz River (mean \pm SD) & Halil River (mean \pm SD) & $\mathbf{F}$ & P-value \\
\hline SL & $98.48 \pm 0.00$ & $98.48 \pm 0.00$ & & - \\
\hline $\mathrm{SnL}$ & $4.28 \pm 0.94$ & $4.48 \pm 1.19$ & 7.37 & 0.01 \\
\hline ED & $4.4 \pm 0.43$ & $4.29 \pm 0.98$ & 12.92 & 0.001 \\
\hline $\mathrm{HL}$ & $29.98 \pm 2.03$ & $30.1 \pm 2.47$ & 2.86 & 0.98 \\
\hline HW & $21.09 \pm 0.83$ & $20.96 \pm 0.99$ & 1.61 & 0.212 \\
\hline HDO & $19.14 \pm 1.02$ & $18.93 \pm 1.1$ & 0.401 & 0.53 \\
\hline $\mathrm{HDE}$ & $10.05 \pm 0.84$ & $10.12 \pm 0.91$ & 1.31 & 0.294 \\
\hline $\mathrm{BH}$ & $19.81 \pm 1.27$ & $19.49 \pm 1.20$ & 0.085 & 0.772 \\
\hline DFL & $53.12 \pm 1.38$ & $53.04 \pm 1.3$ & 0.074 & 0.788 \\
\hline AFL & $33.81 \pm 1.79$ & $33.24 \pm 1.19$ & 1.93 & 0.177 \\
\hline CPL & $8.5 \pm 0.90$ & $8.3 \pm 0.87$ & 0.029 & 0.885 \\
\hline
\end{tabular}

$\mathrm{AFL}=$ anal-fin length, $\mathrm{BD}=$ body depth at dorsal-fin origin, $\mathrm{CPL}=$ caudal peduncle length, $\mathrm{DFL}=$ dorsal-fin length,

$\mathrm{ED}=$ eye horizontal diameter, $\mathrm{HDE}=$ head depth at middle of the eye, $\mathrm{HDO}=$ head depth at posterior edge of the opercle,

$\mathrm{HL}=$ head length, $\mathrm{HW}=$ maximum head width, $\mathrm{SnL}=$ snout length, and $\mathrm{SL}=$ standard length .

and snout had a more ventral position than those of the Sarbaz River one (Figure 3).

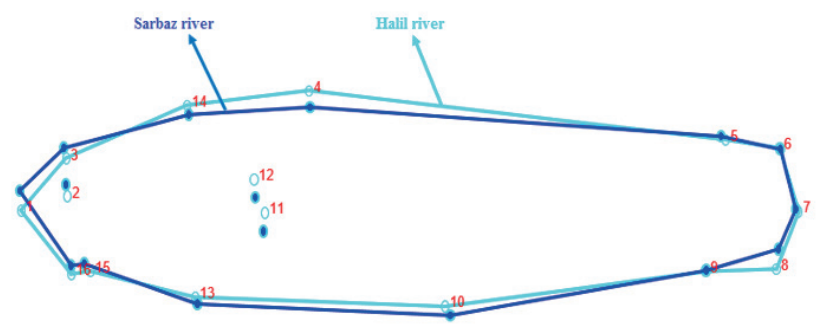

Figure 3. Wireframe diagram consensus body shape graph of Channa gachua populations from the Halil and Sarbaz rivers in GM method.

\section{Traditional Method}

The results showed normality of the data. Levene's test showed significant differences in the snout length and eye diameter (Table 1) $(P<0.05)$. DFA/Hotelling's T-test showed no significant difference between the two studied populations $(P=0.975$, $\mathrm{F}=0.334$, Hotelling's $\mathrm{t}^{2=}=5.64$ ) (Figure 4).

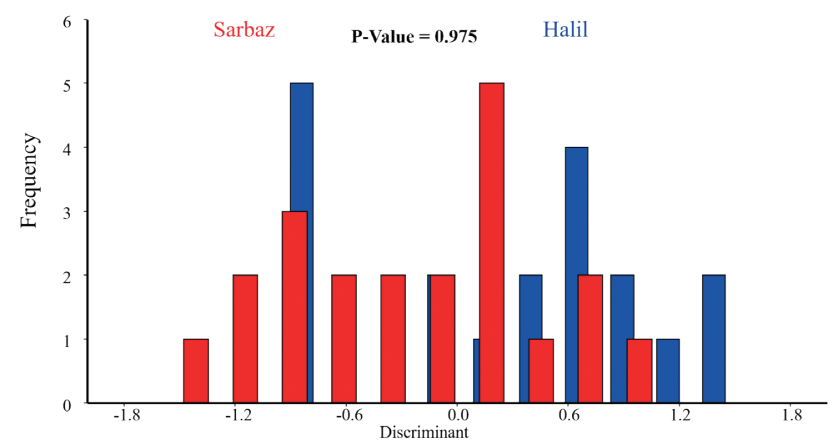

Figure 4. Discriminant function analysis of Channa gachua populations from the Halil and Sarbaz rivers in TM method.
Morphological variations in fishes are considered to be an important adaptive strategy for populations experiencing inconsistent environments such as rivers (20). In addition, fishes show a variety of body form associated with functions such as swimming and feeding to overcome different habitats and lifestyles $(10,21)$. The body shape can even display the lifestyles of a fish. Therefore, based on the diversity of the habitat features or lifestyles, the degree of a biological structure can show a higher plasticity (22), e.g. those fishes with a generalized body shape, are fusiform with a pointed head and forked tail. Therefore, fusiform body designs have a lot of variations in different parts of their body shape.

In the present study, the multivariate analysis did not show a significant difference in TM. However in TM, comparing each morphometric data revealed differences in SnL and ED similar to the results of the GM method. Our findings reject the hypothesis that differences may be related to the body shape type using GM or TM.

However, it is suggested to select a proper method viz GM or $\mathrm{TM}$, prior to the analysis of the data based on the aim of the study and particularly degree of accuracy needed i.e. if we need to find small shape differences within its signification, then we can apply GM, or if our aim is to find traits which show differences, then we can use TM as well. Both methods reveal real differences but GM better signifies difference due to its higher detection ability.

Peer-review: Externally peer-reviewed.

Author Contributions: Conception/Design of study: S.E., A.M.S; Data Acquisition: S.E., A.M.S, S.K.; Data Analysis/Interpretation: S.E., A.M.S., S.K.; Drafting Manuscript: S.E., A.M.S. Critical Revision of Manuscript: S.E.; Final Approval and Accountability: S.E., H.P.; Technical or Material Support: S.E.; Supervision: S.E. 
Conflict of Interest: The authors declare that they have no conflicts of interest.

Financial Disclosure: There are no funders to report for this submission

Acknowledgements: This research was financially supported by the University of Tehran. The authors are thankful for M. Nasri for his help during the sampling.

\section{REFERENCES}

1. Ambrosio PP, Costa C, Sánchez P, Flos R. Stocking density and its influence on shape of Senegalese sole adults. Aqua Inter 2008; 16(4): 333.

2. Jalili P, Eagderi S, Keivany Y. Body shape comparison of Kura bleak (Alburnus filippii) in Aras and Ahar-Chai rivers using geometric morphometric approach. Res Zool 2015; 5(1): 20-4.

3. Karpouzi VS, Stergiou KI. The relationships between mouth size and shape and body length for 18 species of marine fishes and their trophic implications. J fish biol 2003; 62(6): 1353-65.

4. Loy A, Cataudella S, Corti M. Shape changes during the growth of the sea bass, Dicentrarchus labrax (Teleostea: Perciformes), in relation to different rearing conditions. In Advances in morphometrics (1996; 399-405). Springer, Boston, MA.

5. Smith TB, Skulason S. Evolutionary significance of resource polymorphisms in fishes, amphibians, and birds. Annu Rev Ecol Syst 1996, 111-33.

6. Webb PW. Locomotor patterns in theevolution of actinopterygian fishes. Am Zool 1982; 22: 329-42.

7. Mouludi Saleh A, Keivany Y, Jalali SAH. Biometry of Chub (Squalius namak Khaefi et al., 2016) in rivers of Namak Basin. J Experiment Anim Biol 2018; 7(1): 107-18.

8. Radkhah A, Poorbagher $\mathrm{H}$, Eagderi S. Investigation of morphological differences of Capoeta capoeta populations in the upstream and downstream of Zarinerood River in Urmia Lake Basin. J Anim Env 2016; 8(3): 167-74.

9. Salehinia D, Eagderi S, Khorasani NA, Zamani-Faradonbeh M. Impact of Sangban Dam on the morphologicl chaactrestics of Siah mahi (Capoeta gracilis, keyserling, 1864) populations using traditional and geometric morphometrics techniques. J Anim Env 2016; 8(2): 97-104.

10. Eagderi S, Esmaeilzadegan E, Madah A, Body shape variation in riffle minnows (Alburnoides eichwaldii De Filippii, 1863) populations of Caspian Sea basin. J Biosystem Taxon 2013; 5(14): 1-8.
11. Eagderi S, Esmaeilzadegan E, Pirbeigi A. Morphological responses of Capoeta gracilis and Alburnoides eichwaldii populations (Cyprinidae) fragmented due to Tarik Dam (Sefidrud River, Caspian Sea basin, Iran). Iranian J Ichthyol 2014; 1(2): 114-20.

12. Mouludi-Saleh A, Keivany Y. Morphological diversity in three species of Chubs (Squalius spp.) populations in Iranian Basins. Nova Biol Reperta 2018a; 5(2): 192-204.

13. Mouludi-Saleh A, Keivany Y. Morphometric analysis of Squalius namak Khaefi et al. 2016 in Khaznagh and Ghare-Chai rivers. Sri Lanka J Aqua Sci 2018b; 23(2): 173-8.

14. Nasri M, Eagderi S, Farahmand H, Segherloo IH, Body shape comparison of Cyprinion macrostomum (Heckel, 1843) and Cyprinion watsoni (Day, 1872) using geometric morphometric method. Inter J Aqua Biol 2013; 1(5): 240-4.

15. Nasri M, Eagderi S, Keivany $Y$, Farahmand H, Dorafshan S, Nezhadheydari H. Morphological diversity of Cyprinion Heckel, 1843 species (Teleostei: Cyprinidae) in Iran. Iranian J Ichthyol 2018; 5(2): 96-108.

16. Razavipour P, Eagderi S, Poorbagher H, Javanshir Khooi A, Keivany Y. Comparative study of morphological characteristics of Tuini fish (Capoeta damascina) in inland water of Iran using geometic morphometric method. J Fish 2015; 8(1): 79-90.

17. Zamani Faradonbeh M, Eagderi S, Nasri M. Geometrics morphometric comparison of populations of waspi Cabdio morar (Hamilton, 1822) in Mashkil and Mokran basins. Iranian Sci Fish J 2014; 23(2): 57-67.

18. Coad BW, Freshwater Fishes of Iran (Available at http://www. briancoad.com) (accessed on 4 March 2019).

19. Elliott NG, K. Haskard JA. Koslow. Morphometric analysis of orange roughy (Hoplostethus atlanticus) off the continental slope of southern Australia. J Fish Biol 1995; 46:202-20.

20. Zamani Faradonbe M, Eagderi S, Moradi M. Patterns of Body Shape Variation in Capoeta gracilis (Pisces: Cyprinidae) in Relation to Environmental Variables in Sefidrud River Basin, Iran. J Appl Biol Sci 2015; 9(1): 36-42.

21. Langerhans RB, Layman CA, Langerhans AK, DeWitt TJ. Habitatassociated morphological divergence in two Neotropical fish species. Biol J Linn Soc 2003; 80: 689-98.

22. Kassen B, Bell G. Experimental evolution in Chlamydomonas. IV. Selection in Environments that vary through time at different scales. Heredity $1998 ; 80: 732-41$. 